\title{
IMPORTANCE OF SCREENING FOR URINARY TRACT INFECTION IN AFRICAN BLACK DIABETICS
}

\author{
BAH Alpha Oumar, DIALLO Mamadou Dian Mamoudou, KABA Mohamed Lamine, BALDE Mamadou Cellou \\ Department of Nephrology, Donka National Hospital, Conakry.
}

\begin{abstract}
Urinary tract infections are common and often latent in diabetic patients. The objective of this study was to determine the frequency of urinary tract infections and the organisms responsible.

This is a descriptive type prospective study conducted in the Endocrinology and Diabetology ward of Donka University Hospital. All diabetic patients hospitalised from January 3rd to April 4th 2013 were included in the study.

Two hundred and sixty-two diabetics had been screened, $64(24.42 \%)$ had a urinary tract infection - 41 women $(64 \%)$ and 23 men $(36 \%)$. The average age was $56.48 \pm 16.3$ years with a range of $20-90$ years. Urinary tract infections were more frequent between the ages of 45 and 74 (67.20\%). Sixty patients were married, four were single. Fifty-six patients were type 2 diabetes against eight type I diabetes. Urine test strips showed 60 cases of pyuria, 36 cases of nitruria, 21 cases of proteinuria and three cases of hematuria. Organisms identified were: Escherichia coli in 31 cases (48.43\%): 25 women and six men; Klebsiella pneumoniae in 14 cases (21.87\%): nine women and five men; Staphylococcus aureus in 11 cases (17.18\%): six women and five men; and Proteus mirabilis in eight cases (12.51\%): two women and six men. The clinical manifestations were: asymptomatic bacteriuria in 57 cases (89.06\%); acute cystitis in five cases (7.81\%); and acute urethritis in two cases $(3.13 \%)$.
\end{abstract}

Urinary infection in African diabetics is very common. It requires a systematic screening with urine test strips because asymptomatic types are by far the most common. This would allow early treatment and avoid serious complications.

\section{KEYWORDS}

Urinary tract infection, diabetes, screening, Donka National Hospital.

\section{INTRODUCTION}

Urinary tract infections are common in diabetic patients [6] and are often latent with much more severe consequences than in non-diabetics. In our daily practice, urinary tract infection is a major factor of morbidity in diabetic patients. The high frequency of urinary tract infection and the lack of previous studies in our country have motivated this study, with the objective of determining the frequency of urinary tract infection and the type of organisms encountered.

\section{MATERIAL AND METHODS}

This is a descriptive type prospective study conducted in the Endocrinology and Diabetology ward of Donka University
Hospital over a period of three months, from January 3rd to April 4th 2013.

All diabetic patients hospitalised during this period were included in the study. Diabetic outpatients were not included in the study.

On admission, clear and accurate information on urinary tract infection screening were delivered to patients. Initially, urine test strips were used for testing, then for patients whose strips were positive for nitrites and leukocytes with or without proteinuria or hematuria, urine culture tests were performed.

Urinary tract infection was defined as bacteriuria $\geq 100000$ organisms/ml with leucocyturia $\geq 10000 / \mathrm{ml}$. 
The glomerular filtration rate was estimated by the MDRD formula.

\section{RESULTS}

During the study period, 262 subjects with diabetes had been screened, $64(24.42 \%)$ had a urinary tract infection 41 women $(64 \%)$ and 23 men $(36 \%)$. The average age was $56.48 \pm 16.3$ years with a range of $20-90$ years. Urinary tract infection was more frequent between the ages of 45 and 74 years $(67.20 \%)$. Sixty patients were married against four singles. Fifty-six patients were type 2 diabetics against eight with type I diabetes.

Urine strip tests noted 60 cases of pyuria, 36 cases of nitruria, 21 cases of proteinuria and three cases of hematuria.

Organisms identified were:

- $\quad$ Escherichia coli in 31 cases (48.43\%): 25 women and six men;

Klebsiella pneumoniae in 14 cases (21.87\%): nine women and five men;

Staphylococcus aureus in 11 cases (17.18\%): six women and five men;

Proteus mirabilis in eight cases (12.51\%): two women and six men.

The clinical manifestations were: asymptomatic bacteriuria in 57 cases $(89.06 \%)$, acute cystitis in five cases (7.81\%) and acute urethritis in two cases $(3.13 \%)$.

Associated diseases were hypertension in 26 patients, or $40.6 \%$; chronic renal failure in 19 patients, $29.68 \%$ of which 14 had a creatinine clearance between 90 and $60 \mathrm{ml} / \mathrm{min}$ and five had a clearance $<60 \mathrm{ml} / \mathrm{min}$; diabetic retinopathy in two patients, or $3.10 \%$; tuberculosis in one patient, $1.6 \%$; and HIV infection in one patient, $1.6 \%$.

\section{DISCUSSIONS}

In this study two common markers were used as a means of excluding a urinary tract infection - the leukocyte esterase and nitrite test. A study showed that the nitrite test alone was not sensitive enough $(51.9 \%)$ and the leukocyte esterase test was not specific enough (74.7\%) [2]. Thus, we combined the detection of leukocyte esterase and nitrite to eliminate a urinary tract infection if they proved negative.

This study - the first carried out in our country - showed that urinary tract infection was common among diabetics. This rate was lower than that reported by two different studies conducted in Ivory Coast: one noted a frequency of $44.2 \%$ [9] and the other a frequency of $59.2 \%$ [6]. In the same country, a third study reported a frequency of $6.20 \%$ out of 708 diabetic patients [7]. In all cases, urinary tract infection appears to be more common in Africa than in Europe whose frequency is $10 \%[1]$.

In our study, the organism most frequently encountered was
Escherichia coli with a female predominance (25/31), and Proteus with equal frequency in men. Lokrou [7], Kayima [3] and Schrub [8] reported respective frequencies of $55.88 \%$, $66.7 \%$ and $63 \%$ of Escherichia coli infection.

Female morbidity found in this series corroborates the data found in literature [7, 4], as the morbidity of the 45-74 years age group $(67.20 \%)$ was consistent with the literature [7, 5]. It was reported by the same authors that in patients older than 50 years, prostatic hypertrophy and autonomic neuropathy were contributing factors of urinary tract infection. In our study, none of these abnormalities were found in our patients.

The prevalence of type 2 diabetes in our study reflected the distribution of diabetes in the general population, but it seems that the type of diabetes does not influence the frequency of urinary tract infection [5]. Serious complications described in the literature were not observed in our series.

\section{CONCLUSION}

Urinary tract infection in African diabetics is very common. It requires a systematic screening with urine test strips because clinically asymptomatic types are by far the most common. This would allow early treatment and avoiding serious complications.

\section{REFERENCES}

1. De Mouy D, Armengaud DM, Arzouni JP, Berges JL, Infections Urinaires En Pratique De Ville: Étiologies Et Sensibilité Aux Antibiotiques En Fonction Des Antecedents, Presse Médicale, 1999, vol 28, n³0, 1624-1628.

2. Deville WLJM, Yzermans JC, Van Duijn NP, Bezemer PD, van der Windt, Bouter LM, The Urine Dipstick Test Useful To Rule Out Infections. A Meta-Analysis of The Accuracy, BMC Urology, 2004, 4:4.

3. Kayima JK, Otieno LS, Twahir A, Njenga E, Asymptomatic Bacteriuria Among Diabetics Attending Kenyatta National Hospital, East Africa Medical Journal, 1996, 73, 524-526.

4. Lefaivre J, Delabarre M, Heraud G, L'infection Urinaire Chez Le Diabétique, Journal Méd Caen, 1968, 3, 123 124.

5. Legendre P, Merlet M, Tagnard JM, Lacut JT, Aubertain J, L'infection Urinaire Chez. Le Diabétique, Bordeaux Méd, 1979,12, 1353-1356.

6. Lokrou A, Aka Kone DMB, L'infection Urinaire Chez Le Diabétique Africain À Abidjan. Etude Transversale D'une Population De 708 Patients. Biotypage Des Souches d'Escherichia Coli Observes, Revue Française d'Endocrinologie Clinique, 1994, 35, 241-245. 
7. Lokrou A, Diallo A, Toutout T, Ouedraogo Y, Grogabada N, Koutouan A, Complications Du Diabète Sucré En Milieu Hospitalier En Côte d'Tvoire, Revue Française d'Endocrinologie Clinique, 1984, 34, $205-$ 210.

8. Schrub JC, Courtois H, Prodhomme, L'infection Urinaire Chez Le Diabétique, Cahiers de Médecine, 1973, 14, 923-927.
9. Yao H, Binan Y, Sanogo S, Kouakou G, Baradji A, Diallo D, Infection Urinaire Chez. Le Diabétique Noir Africain En Milieu Hospitalier: Fréquence, Aspects Étiologiques Et Thérapentiques, Médecine d'Afrique Noire, 2009, 56, 102-106.

Table: Urinary tract infections by sex

\begin{tabular}{|l|l|l|l|}
\hline GERMS & MEN & WOMEN & TOTAL \\
\hline Escherichia coli & & $25(59.52 \%)$ & 31 \\
\hline Klebsiella pneumoniae & $5(22.73 \%)$ & & 14 \\
\hline Staphylococcus aureus & $5(22.73 \%)$ & $9(21.43 \%)$ & \\
\hline & & $6(14.29 \%)$ & 11 \\
\hline Proteus mirabilis & $6(27.27 \%)$ & & 8 \\
\hline & & $2(4.76 \%)$ & \\
\hline TOTAL & $\mathbf{2 2 ( 1 0 0 \% )}$ & $\mathbf{4 2}(\mathbf{1 0 0} \%)$ & $\mathbf{6 4})$ \\
\hline
\end{tabular}

